\title{
Anxiety and depression among children and young people involved in family justice court proceedings: Iongitudinal national data linkage study
}

Lucy Jane Griffiths*, Joanna Mcgregor, Theodora Pouliou, Rhodri D. Johnson, Karen Broadhurst, Linda Cusworth, Laura North, David V. Ford and Ann John*

\section{Background}

Little is known about mental health problems of children and young people (CYP) involved with public and private law family court proceedings, and how these CYP fare compared to those not involved in these significant disruptions to family life.

\section{Aims \\ This study examined records of depression/anxiety in CYP involved in public and private law proceedings using linked population-level data across Wales.}

\section{Method}

Retrospective e-cohort study. We calculated the incidence of primary-care-recorded depression/anxiety among CYP involved in these proceedings and in a comparison group, using Poisson regression. Depression/anxiety outcomes following proceedings were evaluated using pairwise cox regression, with age- and gender-matched controls of CYP who had no involvement with the courts.

\section{Results}

CYP in the public group had twice the risk of depression (adjusted incidence rate ratio alRR $=2.2 ; 95 \% \mathrm{Cl} 1.9-2.6$ ) and $20 \%$ higher risk of anxiety (alRR $=1.2 ; 95 \% \mathrm{Cl} 1.0-1.5$ ) relative to the comparison group. The private group had $60 \%$ higher risk of depression (alRR $=1.6 ; 95 \% \mathrm{Cl} 1.4-1.7$ ) and 30\% higher risk of anxiety (aIRR $=1.3 ; 95 \% \mathrm{Cl} 1.2-1.4)$. Following private law proceedings, CYP were more likely to have depression (hazard ratio $\mathrm{HR}=1.9 ; 95 \% \mathrm{Cl} 1.7-2.1)$, and anxiety $(\mathrm{HR}=1.4 ; 95 \% \mathrm{Cl} 1.2$ 1.6) than the control group. Following public proceedings, CYP were more likely to have depression ( $\mathrm{HR}=2.1 ; 95 \% \mathrm{Cl} 1.7-2.5)$. Incidence of anxiety or depression following court proceedings was around $4 \%$.

\section{Conclusions}

Findings highlight the vulnerability of CYP involved in family court proceedings and increased risk of depression and anxiety. Schools, health professionals, social and family support workers have a role to play in identifying needs and ensuring CYP receive appropriate support before, during and after proceedings.

\section{Keywords}

Care proceedings; administrative data; data linkage; children; mental health.

\section{Copyright and usage}

(C) The Author(s), 2022. Published by Cambridge University Press on behalf of the Royal College of Psychiatrists. This is an Open Access article, distributed under the terms of the Creative Commons Attribution licence (https://creativecommons.org/ licenses/by/4.0/), which permits unrestricted re-use, distribution, and reproduction in any medium, provided the original work is properly cited.
The Children and Family Court Advisory and Support Service (Cafcass) is a government organisation that represents children's best interests within family court proceedings, with the aim of ensuring that the welfare of the child is central in decisionmaking. Private law family court cases are disputes, usually between parents after relationship breakdown, about arrangements for a child's upbringing, such as where a child should live and/or with whom they should have contact. Public law family court cases are brought by local authorities and relate to the safety or welfare of children and young people (CYP). If local authorities intend to remove a child from his or her parents' care or assume parental responsibility, they must apply for a care order. Care orders are applied for and authorised by the family courts under section 31 of the Children Act 1989. Across England and Wales, 19037 public and 51658 private law cases were initiated in 2018. ${ }^{1}$ The aim of these is to make arrangements for CYP that secure their best possible outcomes; ${ }^{2}$ yet, little is known about the health and wellbeing of those involved with family courts.

CYP involved in these proceedings may have been subject to a range of adverse experiences affecting them directly (e.g. through abuse and neglect) or indirectly, through their living environments

* Equal contribution. (e.g. deprivation, exposure to parental conflict or separation, substance misuse or mental illness). ${ }^{3,4}$ Such events are linked to poorer short- and longer-term development and mental health, ${ }^{3,5}$ poorer social outcomes, educational underachievement and/or other serious disruptions to lives. ${ }^{6}$

There is some evidence regarding the mental health of CYP in care $;{ }^{78}$ however, to our knowledge, no studies have compared those involved in public and private law family court proceedings, and with a general population comparison group, using largescale administrative data. This omission is concerning, given that CYP in both types of court case will have been exposed to very difficult family circumstances and disruptions. Far better evidence is needed to ensure that mental health needs are understood and taken into account in best interest decisions. Studies based on population-level data are persuasive in terms of providing policy makers and practitioners with robust evidence to shape service development.

Population-level data collected routinely by Cafcass Cymru (the Welsh Government organisation responsible for the functions of Cafcass in Wales) $)^{9}$ are available within the privacy-protecting Secure Anonymised Information Linkage (SAIL) Databank, ${ }^{10}$ presenting a unique opportunity for linkage to health data at the individual level to explore mental disorders in CYP involved with 
Cafcass Cymru. The aim of this study was to examine incidence of depression and anxiety in CYP involved in public and private family court proceedings across Wales, compared with CYP not involved in family court proceedings. Given the nature of the longitudinal data available within SAIL, a further aim was to examine risk of depression and anxiety following family court proceedings, controlling for medical histories of these conditions.

\section{Method}

\section{Study design}

This was a retrospective e-cohort study to investigate incidence rates (IRs) and incident rate ratios (IRRs). A matched cohort design was also used to investigate risks of depression and anxiety following initiation of court proceedings.

\section{Data source and linkage}

All data within the SAIL Databank are treated in accordance with the Data Protection Act 2018 and are compliant with the General Data Protection Regulation. During the anonymisation of data sources within the SAIL Databank, individuals are assigned an anonymised linking field (ALF) enabling linkage of person-level data-sets.

The family justice data used for this study included the aforementioned routinely produced extract of administrative case management data maintained by Cafcass Cymru. ${ }^{9}$ Relevant case information for this study included: child's week of birth and gender, and the date and type of court application (public or private).

The Welsh Longitudinal General Practice (WLGP) data contain primary care records for patients registered with a Welsh general practice (GP) for approximately $80 \%$ of practices that supply data to the SAIL Databank. Each record contains information such as Read Codes (hierarchical nomenclature used by primary care physicians to record clinical summary information, i.e. medical diagnoses and symptoms) and event date (date of entry of the Read Code(s)).

Linkage was also made to the Welsh Demographic Service (WDS) data-set (an administrative register of all individuals in Wales who use the National Health Service (NHS)), for creation of our population denominator and to extract demographic information.

\section{Study population}

This study included CYP involved with Cafcass Cymru between 1 January 2011 and 31 December 2018, aged $<18$ years at first recorded court application date. We identified $11545 \mathrm{CYP}$ involved in public law proceedings and 26569 involved in private law proceedings. A further 936 who had been involved in both public and private law proceedings during this period were allocated to the public group. Over $86.9 \%$ (33 933 of 39 050) of these individuals were assigned an ALF enabling linkage of their information to the other data sources within SAIL. The sample was further restricted to those who had a WDS record $(n=33712)$ and were registered with a SAIL-supplying GP for the same period with at least 12 months of continuous primary care data $(n=22565)$. The final sample therefore consisted of 5524 CYP involved in public and 17041 involved in private law proceedings (Fig. 1). Linkage characteristics of the Cafcass cohort in SAIL have been described elsewhere; ${ }^{9}$ further information on the CYP assigned an ALF ( $n=33$ 933) and the final sample (22 565) are provided in supplementary Table 1 (available at https://doi.org/10.1192/bjo.2022.6), indicating greatest differences (i.e. loss of representation) in the public group for those in the two most deprived areas.

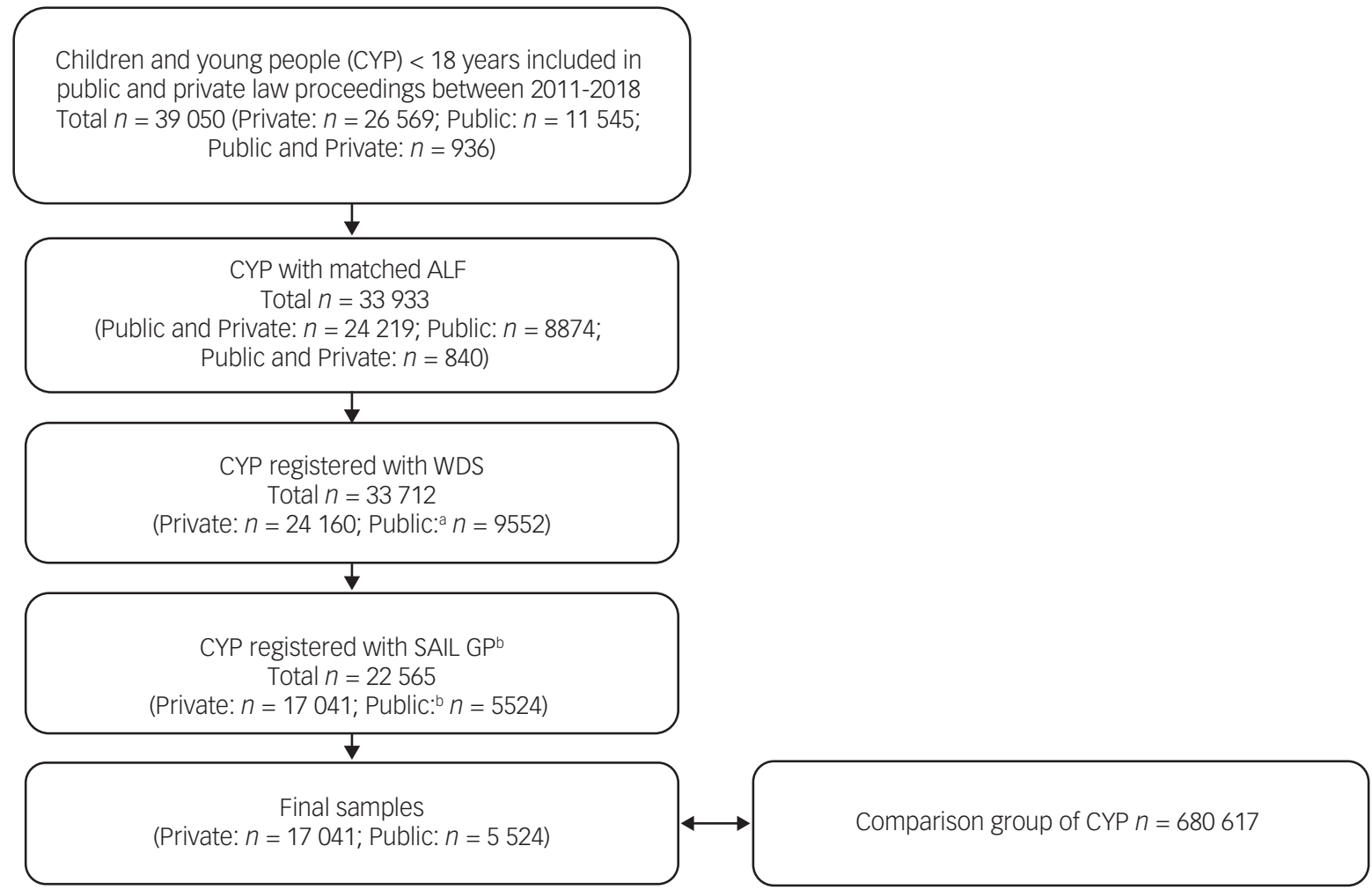

Fig. 1 Flow diagram of study participants.

a. At this stage, children and young people (CYP) involved in both public and private law proceedings were grouped with the CYP involved in public law proceedings. b. CYP who were Welsh residents, registered to a SAlL-supplying general practice (GP) between 1 January 2011 and 31 December 2018 with at least 12 months of continuous general practice data. WDS, Welsh Demographic Service. 
A general comparison group of all 680617 CYP aged $<18$ years who were not involved in family court proceedings was selected from the SAIL Databank for the same period. From this group, we randomly selected ten controls per case matched on age and gender, resulting in a control sample of 225650 CYP for the timeto-event analyses.

\section{Measures}

WLGP records from 1 January 2011 to 31 December 2019 were analysed for the presence of Read Codes indicating diagnoses or symptoms of depression and anxiety based on validated code lists developed by the Adolescent Mental Health Data Platform. ${ }^{11-13}$ A new record of depression or anxiety was defined as an entry with no episode recorded for that condition in the previous 12 months.

Demographic information was collected from the WDS dataset. Age and residential information for each individual was collected based on the start of data collection for each year for the incidence measures and on the date of the first court application for the time-to-event analyses (as described below). Age was described according to categories of under 10 years, $10-14$ and 15-17 years. The Welsh Index of Multiple Deprivation (WIMD) is the Welsh Government's official deprivation measure; WIMD $2014^{14}$ provides deprivation scores for small areas of Wales (lower-layer super output areas (LSOAs)), which are ranked from 1 (most deprived) to 1909 (least deprived) based on a range of domains; each LSOA contained an average population of 1600 people. These were used and grouped into quintiles for this study.

\section{Statistical analyses}

The SAIL Databank was queried using Structured Query Language and analyses were carried out using SPSS statistical software for Windows (version 26).

\section{Incidence measures}

Annual incidence rates (IRs) were calculated using person-years at risk (PYAR) as a denominator. Poisson regression was used to calculate annual IRRs (incident rate ratios) and 95\% confidence intervals (CIs) for the comparison, the public and the private groups and to compare the IRRs between these groups, all models adjusting for age, gender, deprivation and year. The confidence intervals were calculated using the two-tailed mid- $P$ exact method, assuming Poisson distribution. The significance of the variables in the Poisson regression models was assessed using Wald tests. Robust standard errors for the estimated IRRs were used to account for clustering within general practices.

\section{Time-to-event analyses}

Time-to-event analyses were conducted to explore the impact of involvement in public or private court proceedings on risk of depression and anxiety. We used Cox proportional hazard regression, a method that assumes the effect on event to be constant over time, to calculate hazard ratios (HRs) with 95\% confidence intervals. The HRs represent the effects of court involvement versus no court involvement on the baseline risk for either mental health condition during the follow-up period. We modelled the length of time from date of first court application (index) to the first record of depression or anxiety, or to censorship (i.e. the earliest date from: death, leaving a SAIL-registered general practice, leaving Wales or 18th birthday). We fitted separate univariate models for depression and anxiety, and multivariate models adjusting for deprivation (at index date) and previous history of these conditions as covariates. These were stratified by court application type.

\section{Project approvals}

The project proposal was reviewed by the SAIL Information Governance Review Panel (IGRP) at Swansea University. This panel ensures that work complies with information governance principles and represents an appropriate use of data in the public interest. The IGRP includes representatives of professional and regulatory bodies, data providers and the general public. Approval for the project was granted by the IGRP under SAIL project 1040. Cafcass Cymru (the data owner of the family courts data) also approved use of the data for this project.

\section{Results}

\section{Sample characteristics}

Over the study period, more than three times as many CYP were involved in private than public law proceedings ( $n=17041$ and $n$ $=5524$ respectively) (Table 1$) ; 76.7 \%(n=4236)$ of the public law applications were related to section 31 care proceedings. Half (51\%) of public and private applications involved boys, and both public and private applications were also more common in under 10-year olds: $92.1 \%$ of the applicants in the private group fell within this age bracket, and $88.5 \%$ of the public group. Application numbers were higher for those residing in more deprived areas of Wales, almost three-fold for the private group and ten-fold for the public group in the most deprived versus the least deprived areas.

\section{Incidence of depression and anxiety \\ Depression}

Table 2 summarises the number of events (recorded diagnoses or symptoms), incidence rates and adjusted IRRs for depression by gender, age group, deprivation quintile and calendar year. The incidence rates for girls (private: 4.7/1000 PYAR (95\% CI 4.5-4.9); public: $10.4 / 1000$ (95\% CI 9.9-11.0)) were higher than for boys (private: 2.4/1000 (95\% CI 2.3-2.6); public: 2.9/1000 (95\% CI 2.6$3.2)$ ); incidence of depression was therefore also twice as high in girls, compared with boys, in private cases $(\mathrm{IRR}=1.9(95 \% \mathrm{CI}$ 1.6-2.4)) and three times as high in public cases (IRR $=3.1(95 \%$ CI 2.3-4.3)). In the comparison group, girls also had higher rates $(\mathrm{IRR}=2.4(95 \%$ CI $2.3-2.5))$.

Incidence of depression was also higher for older children (Table 2). Incidence was 0.4 cases per 1000 PYAR for those under 10 years of age in both private and public groups, and there was a marked age-related trend with increasing age for both the private

\begin{tabular}{|c|c|c|c|c|c|c|}
\hline & \multicolumn{2}{|c|}{ Comparison } & \multicolumn{2}{|c|}{ Private court } & \multicolumn{2}{|c|}{ Public court } \\
\hline & $n$ & $\%$ & $n$ & $\%$ & $n$ & $\%$ \\
\hline Total & 680617 & & 17041 & & 5524 & \\
\hline \multicolumn{7}{|l|}{ Gender } \\
\hline Male & 348647 & 51.2 & 8744 & 51.3 & 2840 & 51.4 \\
\hline Female & 331970 & 48.8 & 8297 & 48.7 & 2684 & 48.6 \\
\hline \multicolumn{7}{|l|}{ Age group } \\
\hline Under 10 years & 461182 & 67.8 & 15702 & 92.1 & 4888 & 88.5 \\
\hline 10-14 years & 154013 & 22.6 & 1297 & 7.6 & 600 & 10.9 \\
\hline 15-17 years & 65422 & 9.6 & 42 & 0.2 & 36 & 0.7 \\
\hline \multicolumn{7}{|l|}{ Deprivation quintile ${ }^{a}$} \\
\hline Least deprived & 122365 & 18.0 & 2142 & 12.6 & 274 & 5.0 \\
\hline Second least deprived & 108270 & 15.9 & 2311 & 13.6 & 440 & 8.0 \\
\hline Middle deprived & 127366 & 18.7 & 3018 & 17.7 & 785 & 14.2 \\
\hline Second most deprived & 139674 & 20.5 & 3984 & 23.4 & 1283 & 23.2 \\
\hline Most deprived & 164803 & 24.2 & 5272 & 30.9 & 2645 & 47.9 \\
\hline
\end{tabular}




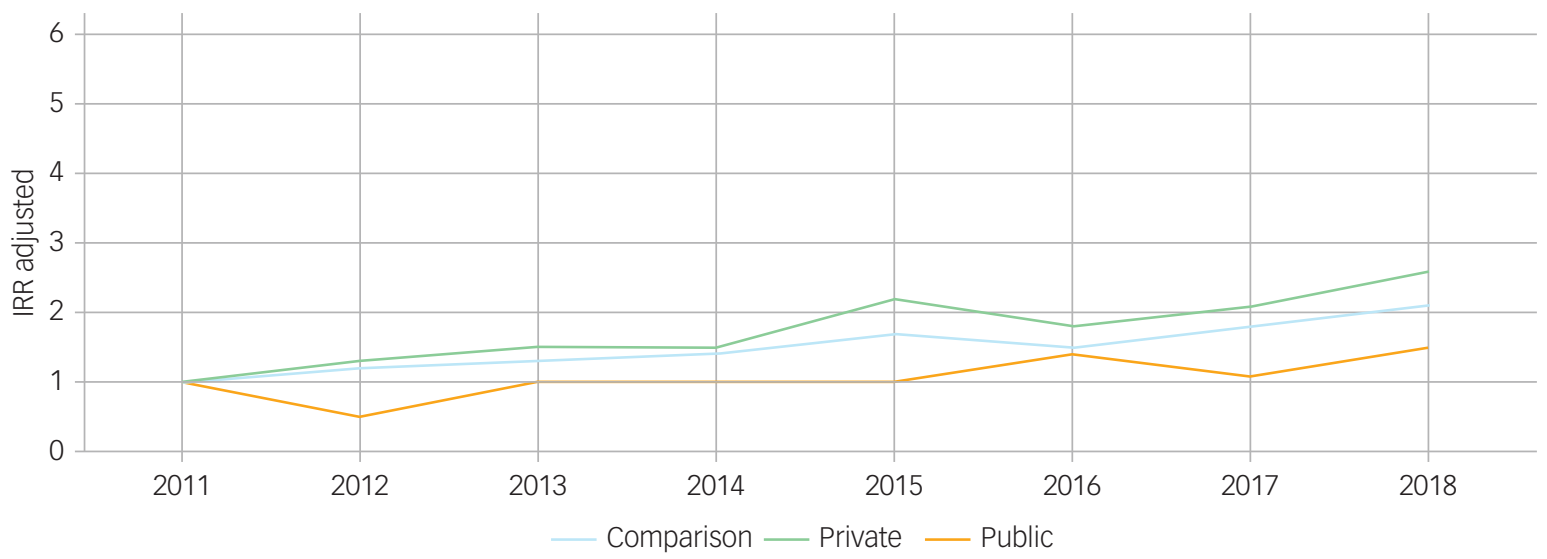

Fig. 2 Adjusted incidence rate ratios (IRRs) of depression over time for children and young people involved in private and public law proceedings and the comparison group.

group (e.g. at age 15-17: $\mathrm{IR}=37.3 / 1000$ (95\% CI 35.3-39.4) and IRR $=75.6(95 \%$ CI $51.3-111.4)$ ) and the public group (e.g. age 15-17: IR $=52.9 / 1000(95 \%$ CI $49.3-56.9)$ and $\mathrm{IRR}=119.4(95 \%$ CI 57.3-248.9)). Again, this upward trend with increasing age is reflected in the comparison group (Table 2).

Adjusted incidence rates of depression did not vary by deprivation quintile for the private or public groups (Table 2). However, for the comparison group incidence was highest in the most deprived areas $(\mathrm{IRR}=1.6(95 \% \mathrm{CI} 1.5-1.7))$ relative to the least deprived areas.

Table 2 and Fig. 2 summarise trends over time, relative to the base year 2011. For the comparison group, rates of depression increased over time, from 2.9/1000 PYAR (95\% CI 2.9-3.0) in 2011 to $6.3 / 1000$ (95\% CI 6.2-6.4) in 2018. Rates of depression in the private group were almost three times as high in 2018 compared with 2011 (for 2018, IRR $=2.6$ (95\% CI 1.3-5.4)). For the public group, rates remained similar over time.

Anxiety

As for depression, compared with boys, rates of anxiety were higher in girls involved in private (IR = 5.4/1000 PYAR (95\% CI 5.2-5.6); $\operatorname{IRR}=1.6(95 \%$ CI $1.3-1.9))$ and in public $(\mathrm{IR}=5.9 / 1000(95 \% \mathrm{CI}$ 5.5-6.3); IRR $=1.5$ (95\% CI 1.1-2.1)) proceedings (Table 3). Again, incidence of anxiety increased with increasing age across all groups (Table 3). The incidence of anxiety stood at around 5 cases per 1000 PYAR across all groups (private, public and

\begin{tabular}{|c|c|c|c|c|c|c|c|c|c|}
\hline & \multicolumn{3}{|c|}{ Comparison $(n=680617)$} & \multicolumn{3}{|c|}{ Private court $(n=17041)$} & \multicolumn{3}{|c|}{ Public court $(n=5524)$} \\
\hline & $\begin{array}{c}\text { Events, } \\
n\end{array}$ & IR (95\% CI) & $\operatorname{IRR}^{\mathrm{a}}(95 \% \mathrm{Cl})$ & $\begin{array}{c}\text { Events, } \\
n\end{array}$ & IR $(95 \% \mathrm{Cl})$ & $\operatorname{IRR}^{\mathrm{a}}(95 \% \mathrm{Cl})$ & $\begin{array}{c}\text { Events, } \\
n\end{array}$ & IR (95\% CI) & $\operatorname{IRR}^{\mathrm{a}}(95 \% \mathrm{CI})$ \\
\hline Total & 17815 & $5(4.9-5)$ & & 470 & $4.3(4.2-4.5)$ & & 152 & $4.7(4.4-4.9)$ & \\
\hline \multicolumn{10}{|l|}{ Gender } \\
\hline Male & 6238 & $3.4(3.4-3.4)$ & 1 & 185 & $3.3(3.1-3.5)$ & 1 & 59 & $3.5(3.2-3.8)$ & 1 \\
\hline Female & 11577 & $6.6(6.6-6.7)$ & $2(1.9-2)^{*}$ & 285 & $5.4(5.2-5.6)$ & $1.6(1.3-1.9)^{*}$ & 93 & $5.9(5.5-6.3)$ & $1.5(1.1-2.1)^{\star \star}$ \\
\hline \multicolumn{10}{|l|}{ Age group } \\
\hline Under 10 years & 2197 & $1.1(1.1-1.1)$ & 1 & 141 & $1.7(1.6-1.8)$ & 1 & 24 & $1.1(0.9-1.2)$ & 1 \\
\hline 10-14 years & 7314 & $7.1(7.1-7.2)$ & $6.7(6.4-7)^{*}$ & 238 & $10.4(10-10.9)$ & $4.8(3.9-6)^{*}$ & 90 & $11.1(10.3-11.9)$ & $10.2(6.4-16.2)^{*}$ \\
\hline 15-17 years & 8304 & $15.7(15.6-15.8)$ & $14.7(14-15.4)^{*}$ & 91 & $21.9(20.4-23.5)$ & $8.6(6.5-11.4)^{*}$ & 38 & $22.8(20.5-25.5)$ & $18.7(10.9-32.1)^{*}$ \\
\hline \multicolumn{10}{|l|}{ Deprivation quintile } \\
\hline Least deprived & 3445 & $5.2(5.1-5.2)$ & 1 & 71 & $5.2(4.8-5.6)$ & 1 & 14 & $6.2(5.2-7.4)$ & 1 \\
\hline $\begin{array}{l}\text { Second least } \\
\text { deprived }\end{array}$ & 2860 & $5(4.9-5.1)$ & $1(0.9-1)$ & 72 & $4.8(4.5-5.2)$ & $1(0.7-1.3)$ & 15 & $4.7(4-5.7)$ & $0.9(0.4-1.8)$ \\
\hline Middle deprived & 3375 & $5(5-5.1)$ & $1(1-1.1)$ & 89 & $4.6(4.3-4.9)$ & $0.9(0.7-1.3)$ & 29 & $5.9(5.2-6.7)$ & $1.1(0.6-2)$ \\
\hline $\begin{array}{l}\text { Second most } \\
\text { deprived }\end{array}$ & 3625 & $4.9(4.9-5)$ & $1(1-1.1)$ & 112 & $4.5(4.2-4.7)$ & $0.9(0.7-1.3)$ & 28 & $3.6(3.2-4.1)$ & $0.7(0.4-1.4)$ \\
\hline Most deprived & 4110 & $4.8(4.7-4.8)$ & $1(1-1.1)$ & 110 & $3.3(3.1-3.5)$ & $0.7(0.5-1)^{\star *}$ & 62 & $4.5(4.1-4.9)$ & $0.9(0.5-1.7)$ \\
\hline \multicolumn{10}{|l|}{ Year } \\
\hline 2011 & 1130 & $2.6(2.5-2.6)$ & 1 & 9 & $0.8(0.7-1)$ & 1 & 6 & $1.7(1.3-2.2)$ & 1 \\
\hline 2012 & 1362 & $3(3-3.1)$ & $1.1(1-1.2)^{* *}$ & 25 & $2(1.8-2.3)$ & $2.3(1.1-4.9)^{* *}$ & 14 & $3.6(3-4.3)$ & $1.8(0.7-4.7)$ \\
\hline 2013 & 1622 & $3.6(3.5-3.7)$ & $1.3(1.2-1.4)^{*}$ & 27 & $2(1.8-2.3)$ & $2.1(1-4.5)$ & 12 & $2.9(2.4-3.6)$ & $1.3(0.5-3.4)$ \\
\hline 2014 & 1978 & $4.4(4.3-4.4)$ & $1.6(1.5-1.8)^{*}$ & 33 & $2.3(2.1-2.6)$ & $2.1(1-4.4)$ & 15 & $3.5(3-4.2)$ & $1.3(0.5-3.5)$ \\
\hline 2015 & 2336 & $5.2(5.1-5.2)$ & $2(1.8-2.1)^{*}$ & 53 & $3.6(3.3-4)$ & $3(1.5-6.1)^{\star *}$ & 13 & $3(2.5-3.7)$ & $0.9(0.4-2.5)$ \\
\hline 2016 & 2593 & $5.7(5.6-5.8)$ & $2.2(2.1-2.4)^{*}$ & 80 & $5.4(5-5.8)$ & $4(2-8.1)^{*}$ & 32 & $7.4(6.6-8.4)$ & $2.1(0.9-5.1)$ \\
\hline 2017 & 3181 & 7 (6.9-7.1) & $2.7(2.5-2.9)^{*}$ & 95 & $6.5(6.1-7)$ & $4.5(2.2-8.9)^{*}$ & 32 & $7.6(6.8-8.6)$ & $2(0.8-4.8)$ \\
\hline 2018 & 3613 & $8.4(8.3-8.5)$ & $3.2(3-3.4)^{*}$ & 148 & $10.7(10.1-11.3)$ & $6(3.1-11.9)^{*}$ & 28 & $7.3(6.4-8.3)$ & $1.8(0.7-4.3)$ \\
\hline
\end{tabular}




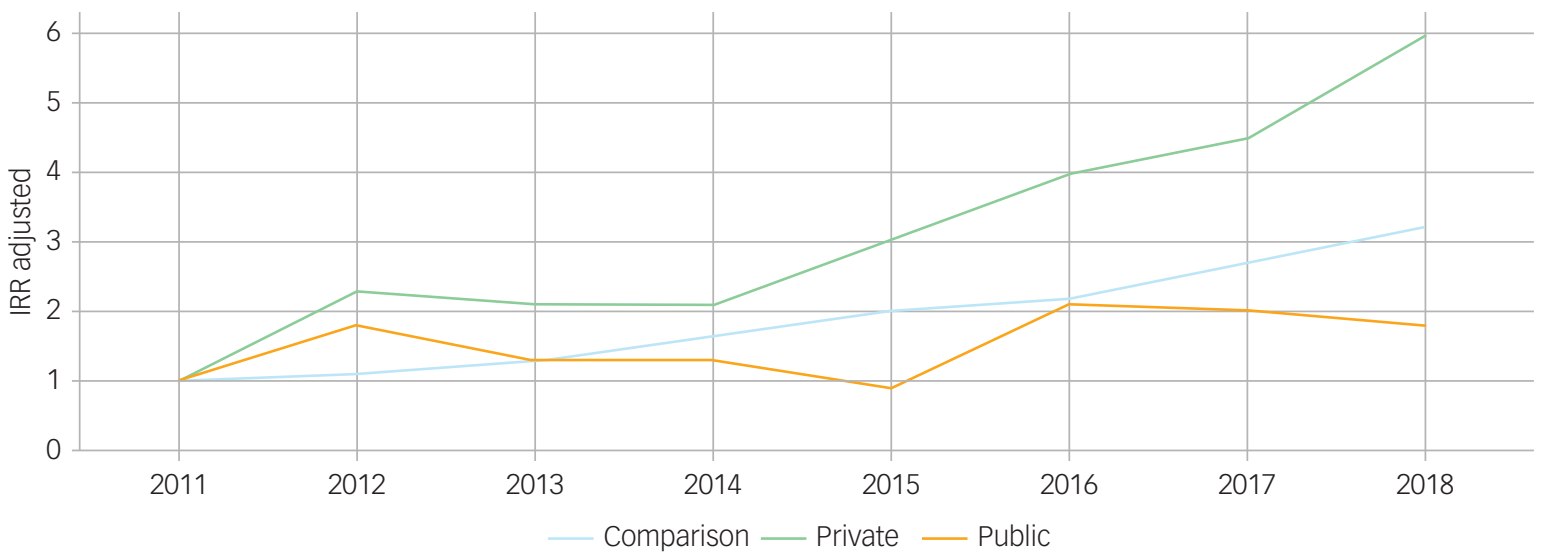

Fig. 3 Adjusted incidence rate ratios (IRRs) of anxiety over time for children and young people involved in private and public law proceedings and the comparison group.

comparison group), again with little difference according to deprivation quintile (Table 3 ).

Trends over time for anxiety are shown in Table 3 and Fig. 3. There was a significant increase in the incidence of anxiety from 2011 to 2018 for the private group: from $\mathrm{IR}=0.8 / 1000$ PYAR (95\% CI $0.7-1.0)$ cases in 2003 to IR $=10.7 / 1000$ (95\% CI $10.1-$ $11.3)$ in $2018(\operatorname{IRR}=6(95 \%$ CI 3.1-11.9)). For the public group, rates of anxiety (ranging from $I R=1.7 / 1000(95 \%$ CI $1.3-2.2)$ in 2003 to a high of IR $=7.6 / 1000(95 \%$ CI 6.8-8.6) in 2017) were fairly stable over the study period (e.g. for 2018 , IRR $=1.8(95 \%$ CI 0.7-4.3)). In contrast, for the comparison group, rates of anxiety were almost three-fold in 2018 (IR $=8.4 / 1000$ (95\% CI 8.3-8.5)) compared with 2011 (IR $=2.6 / 1000(95 \%$ CI $2.5-2.6)$ ) with IRR $=3.2(95 \%$ CI 3.0-3.4)

\section{Comparing public, private and comparison group}

Overall, incidence of depression was higher in the public group (IR $=6.5 / 1000$ PYAR $(95 \%$ CI 6.2-6.8)) than in the private group (IR = $3.5 / 1000$ (95\% CI 3.4-3.7)) and the comparison group ( $\mathrm{IR}=4.6 /$ 1000 (95\% CI 4.6-4.6)) (Table 4 and Fig. 4). However, as can be seen from the adjusted IRRs, rates of depression were twice as high $(\mathrm{IRR}=2.2(95 \%$ CI 1.9-2.6) $)$ in the public group and $60 \%$ higher in the private group (IRR = 1.6 (95\% CI 1.4-1.7)), compared with the comparison group.

Incidence of anxiety was slightly lower in the public (IR $=4.7 /$ 1000 PYAR (95\% CI 4.4-4.9)) and private (IR $=4.3 / 1000$ (95\% CI $4.2-4.5)$ ) groups than in the comparison group (IR $=5.0 / 1000$ (95\% CI 4.9-5.0)). Following adjustment, rates were 30\% higher in the private group (IRR $=1.3(95 \%$ CI $1.2-1.4))$ and $20 \%$ higher in the public group $(\mathrm{IRR}=1.2(95 \%$ CI $1.0-1.5)$ )

\section{Time-to-event}

Characteristics of the cohort and matched control group for the timeto-event analyses are provided in supplementary Tables 2 and 3. CYP involved in private law proceedings were significantly more likely to develop depression than the control group ( $\mathrm{HR}=1.9$ (95\% CI 1.72.1)) and this was also evident in boys and girls separately (Table 5). Similarly, they were more likely to have anxiety ( $\mathrm{HR}=1.4(95 \% \mathrm{CI}$ 1.2-1.6)). CYP involved in public law proceedings were also subsequently more likely to have depression than the control group (HR $=2.1(95 \%$ CI $1.7-2.5))$ but not anxiety ( $\mathrm{HR}=1.2$ (95\% CI $0.9-$ 1.4)). Incidence proportions are also shown in Table 5: $4.2 \%$ of the private and $4.4 \%$ of the public cohorts had a new health record for anxiety or depression following court proceedings.

\section{Discussion}

\section{Summary of main findings}

The incidence of depression and anxiety recorded in primary care was higher for CYP involved in public and private family court proceedings compared with those not involved with family courts. Incidence of both recorded conditions was higher for girls and increased with increasing child age. However, adjusted rates did not vary by our measure of relative deprivation, as shown in the general population, suggesting heightened vulnerability of these CYP across the board. Regarding trends over time from 2011 to 2018, rates of depression and anxiety increased for those involved in private cases, mirroring trends in the comparison group, but they remained stable for those involved in public cases, perhaps reflecting differences in help-seeking behaviours.

Table 4 Total number of events (recorded diagnoses or symptoms) and incidence of depression and anxiety among children and young people involved in private and public law proceedings, and the comparison group

\begin{tabular}{|c|c|c|c|c|c|c|}
\hline & \multicolumn{3}{|c|}{ Depression } & \multicolumn{3}{|c|}{ Anxiety } \\
\hline & Events, $n$ & IR $(95 \% \mathrm{Cl})$ & $\mathrm{IRR}^{\mathrm{a}}(95 \% \mathrm{Cl})$ & Events, $n$ & IR (95\% Cl) & $\operatorname{IRR}^{\mathrm{a}}(95 \% \mathrm{Cl})$ \\
\hline Total & 17081 & & & 18437 & & \\
\hline Comparison & 16485 & $4.6(4.6-4.6)$ & $1(0-0)$ & 17815 & 5 (4.0-9-5) & $1(0-0)$ \\
\hline Private court & 384 & $3.5(3.4-3.7)$ & $1.6(1.4-1.7)^{\star}$ & 470 & $4.3(4.2-4.5)$ & $1.3(1.2-1.4)^{*}$ \\
\hline Public court & 212 & $6.5(6.2-6.8)$ & $2.2(1.9-2.6)^{\star}$ & 152 & $4.7(4.4-4.9)$ & $1.2(1.0-1.5)^{*}$ \\
\hline
\end{tabular}




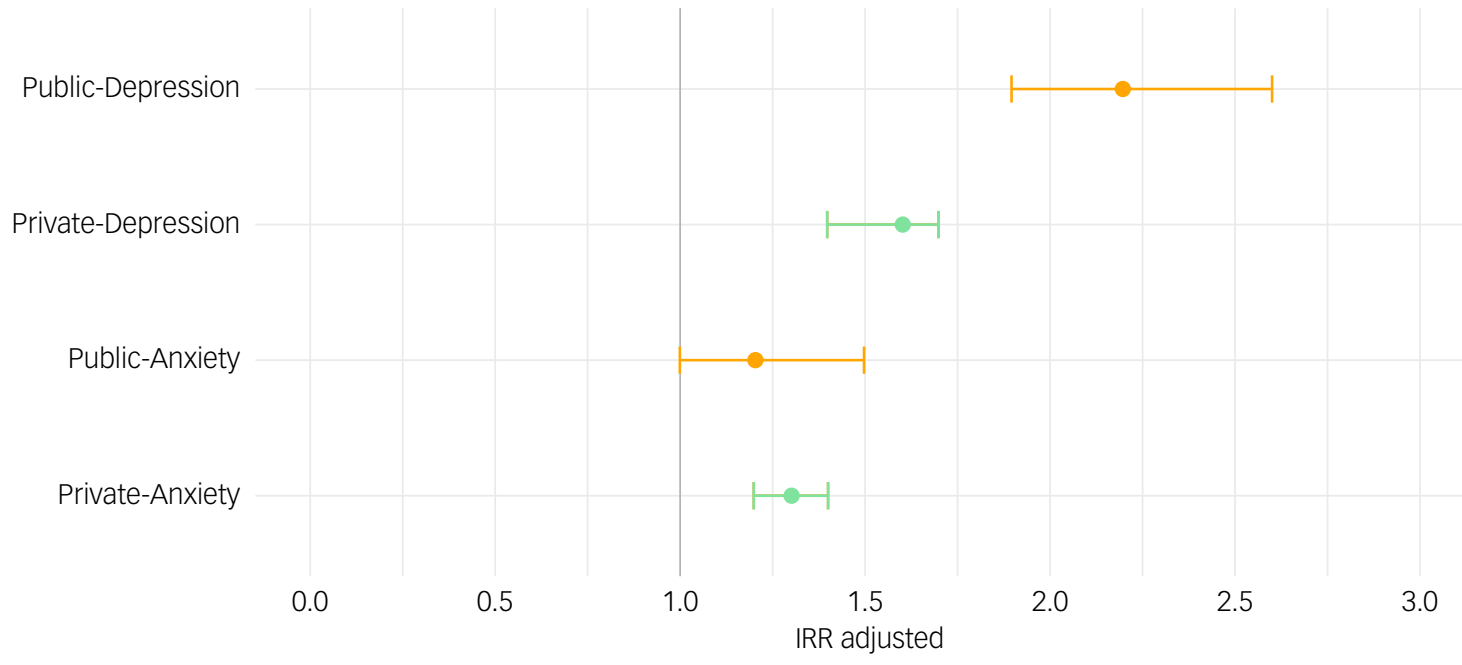

Fig. 4 Adjusted incidence rate ratios (IRRS) of anxiety and depression for children and young people involved in private and public law proceedings.

Table 5 Time-to-event analyses for anxiety and depression among children and young people (CYP) before and after private and public law proceedings

\begin{tabular}{|c|c|c|c|c|c|c|c|c|c|}
\hline & \multirow[b]{2}{*}{$\begin{array}{c}\text { CYP, } \\
n\end{array}$} & \multicolumn{4}{|c|}{ Anxiety } & \multicolumn{4}{|c|}{ Depression } \\
\hline & & $\begin{array}{c}\text { Events, } \\
n(\%)\end{array}$ & $\begin{array}{c}\text { History of } \\
\text { anxiety, }{ }^{a} n(\%)\end{array}$ & $\begin{array}{l}\text { Unadjusted } \\
\text { HR }(95 \% \mathrm{Cl})\end{array}$ & $\begin{array}{c}\text { Adjusted }^{\mathrm{b}} \\
\mathrm{HR}(95 \% \mathrm{Cl})\end{array}$ & $\begin{array}{c}\text { Events, } \\
n(\%)\end{array}$ & $\begin{array}{c}\text { History of } \\
\text { depression, }{ }^{c} n(\%)\end{array}$ & $\begin{array}{l}\text { Unadjusted } \\
\text { HR }(95 \% \mathrm{Cl})\end{array}$ & $\begin{array}{l}\text { Adjusted }^{d} \\
\text { HR }(95 \% \mathrm{Cl})\end{array}$ \\
\hline \multicolumn{10}{|c|}{ Private court } \\
\hline All & 17041 & $384(2.3)$ & $13(3.4)$ & $1.4(1.2-1.5)^{\star}$ & $1.4(1.2-1.6)^{*}$ & $328(1.9)$ & $15(4.6)$ & $2.0(1.7-2.2)^{\star}$ & $1.9(1.7-2.1)^{\star}$ \\
\hline Male & 8744 & $148(1.7)$ & & $1.4(1.2-1.7)^{\star}$ & $1.4(1.2-1.7)^{\star}$ & $113(1.3)$ & & $2.1(1.7-2.5)^{\star}$ & $2.0(1.7-2.5)^{*}$ \\
\hline Female & 8297 & $236(2.8)$ & & $1.4(1.2-1.6)^{*}$ & $1.6(1.2-1.6)^{*}$ & $215(2.6)$ & & $1.9(1.6-2.2)^{\star}$ & $1.8(1.6-2.1)^{*}$ \\
\hline \multicolumn{10}{|c|}{ Public court } \\
\hline All & 5524 & $100(1.8)$ & $10(10.0)$ & $1.2(1.0-1.5)$ & $1.2(0.9-1.4)$ & $141(2.6)$ & $14(9.9)$ & $2.3(1.9-2.8)^{\star}$ & $2.1(1.7-2.5)^{\star}$ \\
\hline Male & 2840 & $39(1.4)$ & & $1.4(1.0-1.9)$ & $1.4(1.0-1.9)$ & $32(1.1)$ & & $1.7(1.1-2.4)^{\star *}$ & $1.5(1.0-2.3)^{\star \star *}$ \\
\hline Female & 2684 & $61(2.3)$ & & $1.1(0.8-1.4)$ & $1.1(0.8-1.4)$ & $109(4.1)$ & & $2.6(2.1-3.3)^{*}$ & $2.3(1.9-2.9)^{\star}$ \\
\hline \multicolumn{10}{|c|}{$\begin{array}{l}\text { HR, hazard ratio; Cl, confidence interval. } \\
\text { a. History of anxiety in those with a diagnosis following court proceedings. } \\
\text { b. Adjusted for previous history (ever) of anxiety and deprivation. } \\
\text { C. History of depression in those with a diagnosis following court proceedings. Numbers not provided for males and females separately owing to the small numbers (disclosure risk). } \\
\text { d. Adjusted for previous history (ever) of depression and deprivation. }\end{array}$} \\
\hline
\end{tabular}

The results of our time-to-event analyses, focusing on occurrence of new diagnoses or symptoms of depression or anxiety following court involvement - and taking into account previous medical history - suggests that CYP involved in private law proceedings were more likely to have depression or anxiety than the control group. Those involved in public law proceedings were subsequently more likely to have depression. Just over $4 \%$ had anxiety or depression.

\section{Study strengths and limitations}

This is the first time that population-level family law records have been linked to health data sources in Wales to examine mental health outcomes for CYP, enabled through the SAIL Databank. However, studies based on administrative data are limited by the scope and quality of available data, which are collected primarily for administrative rather than research purposes.

Limitations of the Cafcass Cymru data-set have been previously described. ${ }^{9}$ We acknowledge the possibility of some selection bias, which can occur if subgroups of individuals have different linkage rates; ${ }^{15}$ however, $87 \%$ of the Cafcass Cymru records were successfully matched in SAIL, enabling linkage to health records, and we report on characteristics of the final sample with GP data. This study reports on problems only for CYP who had at least 12 months of GP data and who were thus included in the final sample; there is therefore a possibility that we have excluded children with poorer mental health due to residential mobility, ${ }^{16}$ with mobility more common in CYP involved in public law proceedings. ${ }^{17}$ Further, we only report on problems both known to the healthcare practitioners and coded into patient records; our figures are therefore likely an underestimate of the true numbers of CYP with anxiety and depression. The longitudinal nature of health records has, however, permitted exploration of outcomes of newly diagnosed mental health problems following court proceedings.

A study limitation is the lack of data on the study participants (e. g. ethnicity and other sociodemographic information such as parental educational level), limiting a fuller description of the cohort and our ability to adjust for these factors. Although our time-to-event analysis included deprivation data based on the date of first court application and therefore is likely to be for the family address, the incidence analysis was based on annual data and may include deprivation data based on placement address following a care order, so the latter should be interpreted with more caution in the public law population. Further, there was a lack of information regarding interventions received following involvement with the family courts. The majority of private law applications are for child arrangement orders ${ }^{18}$ but this study has not explored the 
nature of these or profiles of those involved in single or repeat cases. Similarly, we have not examined legal outcomes for those involved in public law proceedings, which may, for example, involve an order for permanent removal from parents and varying placements, such as placed for adoption. For the small proportion of participants who were adopted, NHS registration numbers will also have changed and will therefore have been lost to follow-up. The circumstances of the different orders can clearly have a wide-ranging impact on emotional health. Further analyses are therefore warranted to understand the impact of court involvement in greater depth. Acquisition of further data-sets from local authorities (such as social services) with linkage to existing data within the SAIL Databank will facilitate this future research.

\section{Comparison with previous literature}

Recent evidence linking health and Cafcass Cymru records reports on heightened mental health problems of mothers involved in public law proceedings; ${ }^{19}$ no previous large-scale studies have used routine administrative data to examine or compare similar problems experienced by CYP involved in public or private family court proceedings across Wales.

Based on other study types, there is more robust evidence that parental conflict that is frequent, intense, poorly resolved and about the child is associated with multiple negative outcomes for children. ${ }^{20,21}$ Bream et $\mathrm{al}^{22}$ reported high levels of distress among children involved in parental disputes regarding child arrangements and, based on Cafcass welfare records for private family law proceedings, Macdonald ${ }^{23}$ reports on a lack of consideration of children's accounts in court recommendations and therefore failure in the system to identify those at risk for mental health problems.

Investigating the impact of public law proceedings on mental health, Famularo et $\mathrm{al}^{24}$ showed that post-traumatic stress disorder in children (aged 6-12) was correlated with other anxiety and psychotic disorders and presence of suicidal ideation. Hunt et $\mathrm{al}^{25}$ assessed outcomes for abused and neglected children placed in kinship care (with family or friends): more than half were manifesting emotional or behavioural difficulties. Mulcahy et $\mathrm{al}^{26}$ also examined change in children's adaptation and well-being after care proceedings; although this improved, resolving the impact of maltreatment remained a complex 'work in progress'. Ford et $\mathrm{al}^{7}$ combined data from Meltzer and colleagues' surveys of looked after British children (children looked after by local authorities) and of British children in private households and found higher levels of psychiatric disorder in children in local authority care and, a more recent survey of young people in care in Wales ${ }^{27}$ reports lower well-being than those not in care, with those in residential care having the lowest well-being scores.

Mental health problems are of growing concern and account for a large proportion of the disease burden in young people generally; findings from the 2017 population-level survey of child and adolescent mental health in England estimated that that 1 in 12 (8.1\%) 5- to 19-year-olds had an emotional disorder such as anxiety or depression; ${ }^{28}$ rates also increased with age, and the disorders were more common in girls and among those living in households with the lowest household incomes. Our estimate of just over $4 \%$ for anxiety and depression reflects our calculation of incidence (new cases), inclusion of younger children and, of course, CYP who presented to health services for these problems rather than self-reported estimates.

\section{Implications}

Further work is needed to capture the full range of mental health difficulties experienced. A better understanding of substance misuse and other problems (such as self-harm) will contribute to a better understanding of the scale and depth of problems, which the family courts must take into account during proceedings and in child placement beyond proceedings. Children's mental health needs are a significant factor in placement stability/instability. ${ }^{29}$ Further, to complete the picture, future research should examine associations in the opposite direction, i.e. the impact of having a child with mental health problems on parental conflict, separation and, for those who cannot agree on child arrangements, private law applications.

Welsh Government is committed to mental health support for CYP. ${ }^{30}$ Progress is being made with schools embedding health and well-being into the curriculum and adopting a whole-school approach to support pupils. Although this may capture vulnerable CYP involved with family courts, they may also benefit from improvements within health and local government (including social services). The capacity of local primary mental health support services remains a significant concern in terms of both access to crisis and out-of-hours services across Wales and, more generally, limited support/treatment options for CYP who need help but do not meet the threshold for specialist mental health or neurodevelopmental services. ${ }^{30}$ The Social Services and Wellbeing (Wales) Act 2014 requires social care and health professionals to work together to support the needs of these vulnerable CYP. Careful thought therefore needs to be given to how the system impacts on children already experiencing heightened vulnerability and in particular whether there is a way for the system to act as a gateway to appropriate support in situations where these issues are identified. Greater mental health assessment of CYP throughout their journey in the family justice system is required, as is more training and more effective sharing of information to help services and organisations work together.

Although the overall trend in the volume of private law applications has been modestly upwards over the past decade, there has been a steeper rise in public law applications, particularly care proceedings. ${ }^{18,31}$ This increase in family court cases means that increasing numbers of vulnerable CYP are at risk of depression and anxiety.

Lucy Jane Griffiths $(\mathbb{D}$, Population Data Science, Swansea University Medical School, UK; Joanna Mcgregor, Population Data Science, Swansea University Medical School, UK. Theodora Pouliou, Population Data Science, Swansea University Medical School, UK. Rhodri D. Johnson, Population Data Science, Swansea University Medical School,

UK; Karen Broadhurst, Centre for Child \& Family Justice Research, Lancaster University, UK; Linda Cusworth, Centre for Child \& Family Justice Research, Lancaster University, UK; Laura North, Population Data Science, Swansea University Medical School, UK; David V. Ford, Population Data Science, Swansea University Medical School, UK; Ann John (D, Population Data Science, Swansea University Medical School, UK

Correspondence: Lucy Jane Griffiths. Email: lucy.griffiths@swansea.ac.uk

First received 9 Jun 2021, final revision 7 Jan 2022, accepted 9 Jan 2022

\section{Supplementary material}

Supplementary material is available online at https://doi.org/10.1192/bjo.2022.6.

\section{Data availability}

The data used in this study are available from the Secure Anonymised Information Linkage (SAIL) Databank at Swansea University, Swansea, UK, which is part of the national e-health records research infrastructure for Wales. Those wishing to access data should follow the application process guidelines available at: www.saildatabank.com/application-process.

\section{Acknowledgements}

L.J.G., R.D.J., L.C., L.N. and K.B. are part of the Family Justice Data Partnership (FJDP), a collaboration between Lancaster University and Swansea University. We thank other members of the FJDP, including K. Jones, J. Smart, A. Akbari and S. Thompson (Swansea University), and B. Alrouh, S. Doebler, R. Pattinson and J. Harwin (Lancaster University). We would like to acknowledge all the data providers who make data available for research. We to thank the following people/organisations for their support with this study: L. Harker, Director, Nuffield 
Family Justice Observatory; Cafcass Cymru; Administrative Data Research Centre Wales; and Welsh Government.

\section{Author contributions}

All authors contributed to the conception and design of this work. J.M. performed the analysis under A.J.'s supervision, with L.J.G., R.D.J. and A.J. interpreting the results. T.P. conducted the literature review for this manuscript. L.J.G. drafted the first iteration of the manuscript. All authors critically reviewed the manuscript, provided important intellectual input, approved the final version and agreed to be accountable for their contributions.

\section{Funding}

The Nuffield Family Justice Observatory (Nuffield FJO) funded L.J.G. R.D.J. L.C. and K.B. on this project $(\mathrm{FJO} / 43766)$. This work was also supported by the Adolescent Mental Health Data Platform (ADP), which is funded by MQ Mental Health Research Charity (grant reference: MQBF/3 ADP) and by the Medical Research Council (MRC) Pathfinder (MC_PC_17211). The views expressed are entirely those of the authors and should not be assumed to be those of the Nuffield FJO, ADP, MQ Mental Health Research Charity or the MRC.

\section{Declaration of interest}

\section{References}

1 Ministry of Justice. Family Court Statistics Quarterly, England and Wales, Annual 2018 including October to December 2018. Ministry of Justice, 2018 (https://assets.publishing.service.gov.uk/government/uploads/system/uploads/ attachment_data/file/789792/FCSQ_October_to_December_2018_-_final.pdf).

2 Dickens J, Masson J, Garside L, Young J, Bader K. Courts, care proceedings and outcomes uncertainty: the challenges of achieving and assessing "good outcomes" for children after child protection proceedings. Child Fam Soc Work 2019; 24: 574-81.

3 Hughes K, Bellis MA, Hardcastle KA, Sethi D, Butchart A, Mikton C, et al. The effect of multiple adverse childhood experiences on health: a systematic review and meta-analysis. Lancet Public Health 2017; 2: e356-66.

4 Webb CJR, Bywaters P, Elliott M, Scourfield J. Income inequality and child welfare interventions in England and Wales. J Epidemiol Community Health 2021; 75: 251-7.

5 Kerker BD, Zhang J, Nadeem E, Stein RE, Hurlburt MS, Heneghan A, et al. Adverse childhood experiences and mental health, chronic medical conditions, and development in young children. Acad Pediatr 2015; 15: 510-7.

6 Patel V, Flisher AJ, Hetrick S, McGorry P. Mental health of young people: a global public-health challenge. Lancet 2007; 369: 1302-13.

7 Ford T, Vostanis P, Meltzer H, Goodman R. Psychiatric disorder among British children looked after by local authorities: comparison with children living in private households. Br J Psychiatry 2007; 190: 319-25.

8 Baldwin $\mathrm{H}$, Biehal $\mathrm{N}$, Cusworth L, Wade J, Allgar V, Vostanis P. Disentangling the effect of out-of-home care on child mental health. Child Abuse Negl 2019; 88: 189-200.

9 Johnson RD, Ford DV, Broadhurst K, Cusworth L, Jones KH, Akbari A, et al. Data Resource: population level family justice administrative data with opportunities for data linkage. Int J Popul Data Sci 2020; 9: 1339.

10 Jones $\mathrm{KH}$, Ford DV, Thompson S, Lyons R. A Profile of the SAIL databank on the UK secure research platform. Int J Popul Data Sci 2019; 4: 1134

11 Adolescent Mental Health Data Platform. The Platform (https://adolescentmentalhealth.uk/Platform [cited 28 Feb 2020]).

12 John A, McGregor J, Fone D, Dunstan F, Cornish R, Lyons RA, et al. Case-finding for common mental disorders of anxiety and depression in primary care: an external validation of routinely collected data. BMC Med Inform Decis Mak 2016; 16: 35

13 Cornish RP, John A, Boyd A, Tilling K, Macleod J. Defining adolescent common mental disorders using electronic primary care data: a comparison with outcomes measured using the CIS-R. BMJ Open 2016; 6: e013167.

14 Welsh Government. Welsh Index of Multiple Deprivation (WIMD) 2014 - Summary: Revised 12 August 2015. Welsh Government, 2015.

15 Bohensky M. Bias in data linkage studies. InMethodological Developments in Data Linkage (eds K Harron, H Goldstein, C Dibben): 63-82. John Wiley \& Sons, 2016.

16 Tseliou F, Maguire A, Donnelly M, O'Reilly D. The impact of childhood residential mobility on mental health outcomes in adolescence and early adulthood: a record linkage study. J Epidemiol Community Health 2016; 70: 278-85.

17 Roe A. What's the household composition of families in the family justice system? Linking data to fill the evidence gaps. Nuffield Family Justice Observatory, 2021 (https://www.nuffieldfjo.org.uk/news/data-linkage-household-composition-family-justice-system [cited 16 Nov 2021]).

18 Cusworth L, Bedston S, Trinder L, Broadhurst K, Pattinson B, Johnson RD, et al. Uncovering Private Family Law: Who's Coming to Court in Wales? Nuffield Family Justice Observatory, 2020.

19 Griffiths L, Johnson RD, Broadhurst K, Bedston S, Cusworth L, Alrouh B, et al. Maternal health, pregnancy and birth outcomes for women involved in care proceedings in Wales: a linked data study. BMC Pregnancy Childbirth 2020; 20: 697.

20 Acquah D, Sellers R, Stock L, Harold G. Inter-Parental Conflict and Outcomes for Children in the Contexts OF Poverty and Economic Pressure. Early Intervention Foundation, 2017

21 Harold G, Acquah D, Sellers R, Chowdry H, Feinstein L. What Works to Enhance Inter-Parental Relationships and Improve Outcomes for Children. Department for Work and Pensions, 2016

22 Bream V, Buchanan A. Distress among children whose separated or divorced parents cannot agree arrangements for them. Br J Soc Work 2003; 33: 227-38.

23 Macdonald GS. Hearing children's voices? Including children's perspectives on their experiences of domestic violence in welfare reports prepared for the English courts in private family law proceedings. Child Abuse Negl 2017; 65: $1-13$.

24 Famularo R, Fenton $\mathrm{T}$, Kinscherff R, Augustyn M. Psychiatric comorbidity in childhood post traumatic stress disorder. Child Abus Neg/ 1996; 20: 953-61.

25 Hunt J, Waterhouse S, Lutman E. Keeping them in the family: outcomes for abused and neglected children placed with family or friends carers through care proceedings. Research Brief. BAAF, 2008

26 Mulcahy G, Badger J, Wright H, Erskine C. 'What happened next': a study of outcomes for maltreated children following care proceedings. Adopt Foster 2014; 38: $314-30$.

27 Anthony R. Young People 'Looked After' in Wales: findings from the 2017/18 Health Behaviour in School-aged Children Survey and School Health Research Network Student Health and Wellbeing Survey. Cardiff University, 2020.

28 NHS Digital. Mental health of children and young people in England, 2017 [PAS] NHS Digital, 2018 (https://digital.nhs.uk/data-and-information/publications/ statistical/mental-health-of-children-and-young-people-in-england/2017/2017 [cited 8 Sep 2020]).

29 Harwin J, Simmonds J, Broadhurst K, Brown R. Special Guardianship: a Review of the English Research Studies. Nuffield Family Justice Observatory, 2019.

30 Children, Young People and Education Committee. Mind over Matter: Two Years On. Welsh Parliament, 2020.

31 Alrouh B, Broadhurst K, Cusworth L, Griffiths LJ, Johnson RD, Akbari A, et al. Born into Care: Newborns and Infants in Care Proceedings in Wales. Nuffield Foundation, 2019
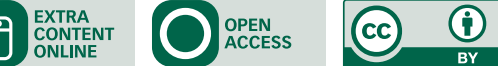